\title{
Computação e Comunidade: Uma Proposta de Educação em Computação para o Sétimo Ano do Ensino Fundamental II
}

\author{
Luis Gustavo J. Araújo ${ }^{1}$, Bianca L. Santana ${ }^{1}$, Roberto A. Bittencourt ${ }^{1}$ \\ ${ }^{1}$ UEFS - Universidade Estadual de Feira de Santana \\ Av. Transnordestina, s/n, Novo Horizonte \\ Feira de Santana - BA, Brasil - 44036-900 \\ \{luisaraujo.ifba,biancasantana.ls\}@gmail.com, roberto@uefs.br
}

\begin{abstract}
Appropriate teaching materials are fundamental to popularizing computing in K-12 education. This paper presents a proposal of a textbook for the seventh grade of middle school, based on reference curricula and guidelines. The book uses an approach based on unplugged activities, games, geometric figures, and the use of the Scratch tool and its plugins. Results of preliminary use of some of the materials point to an adequate didactic sequence and ease of comprehension.
\end{abstract}

Resumo. Materiais didáticos apropriados são fundamentais para a popularização da computação na educação básica. Este trabalho apresenta uma proposta de um livro didático de computação para o sétimo ano do Ensino Fundamental II baseado em diretrizes e referenciais curriculares da área. O livro utiliza uma abordagem baseada em computação desplugada, jogos e figuras geométricas e uso de ferramenta Scratch e seus plugins. Os resultados da aplicação preliminar de parte dos materiais aponta para uma sequência didática adequada e facilidade de compreensão.

\section{Introdução}

A disseminação da computação nas vidas das pessoas leva à necessidade de formação de estudantes na área deste o ensino fundamental. A Sociedade Brasileira de Computação tem atuado política e academicamente para convencer as autoridades educacionais brasileiras a introduzir a computação na educação básica, produzindo documentação como os os Referenciais de Formação em Computação: Educação Básica [SBC 2017].

Entretanto, livros didáticos sobre computação adequados ao ensino fundamental ainda não são facilmente encontrados na literatura nacional, apesar da profusão de trabalhos acadêmicos na área [Santos et al. 2018]. Esta ausência levou os autores deste artigo a criar um projeto para construir um conjunto de livros didáticos para o Ensino Fundamental II brasileiro. Como primeiro resultado deste desafio, já apresentamos nossa proposta de currículo e materiais didáticos para o sexto ano do ensino fundamental, intitulado Computação e Eu [Santana et al. 2019].

No presente artigo, apresentamos a segunda parte de nosso trabalho: uma proposta de currículo e materiais didáticos para o sétimo ano do ensino fundamental. O currículo proposto é baseado nos eixos temáticos e resultados de aprendizagem do currículo da CSTA [Seehorn et al. 2011], e o livro é baseado em atividades desplugadas, nos domínios de jogos e figuras geométricas, no uso de linguagens de blocos, no desenvolvimento do pensamento computacional e na familiarização com conceitos de computação. 
VIII Congresso Brasileiro de Informática na Educação (CBIE 2019)

Anais do XXV Workshop de Informática na Escola (WIE 2019)

\section{Fundamentação Teórica}

A computação impacta hoje diversas áreas do conhecimento, modificando e criando profissões. Por isso, torna-se cada vez mais importante não apenas entender como computadores funcionam ou usar ferramentas de escritório, mas também como utilizar a computação para resolver problemas [Barr et al. 2011]. Dois conceitos são essenciais neste contexto: pensamento computacional, relacionado com o raciocínio usado para resolver problemas [Wing 2006] e fluência digital, relacionado com a criação de soluções computacionais [Resnick et al. 2009, Guzdial 2004]. Estes dois conceitos são pilares na construção dos materiais apresentados neste trabalho.

O movimento de criação de currículos de computação para a educação básica tem crescido no mundo. Diversos países têm adotado currículos de Computação para as escolas, como é o caso dos referenciais da CSTA, nos Estados Unidos [Seehorn et al. 2011]. Iniciativas similares ocorrem em diversos países, tais como Israel [Hazzan et al. 2008], Reino Unido, Nova Zelândia, Alemanha, Índia e Coreia do Sul [Royal Society 2012].

De forma pulverizada, o Brasil vem adotando currículos de computação na educação básica similares aos encontrados fora do pais. Diversos pesquisadores e instituições têm proposto abordagens em escolas visando o exercício e aprimoramento do pensamento computacional e da fluência digital na educação básica [Santos et al. 2018]. Em 2017, a Sociedade Brasileira de Computação (SBC) criou referenciais curriculares de computação específicos para a Educação Básica [SBC 2017].

De modo similar ao proposto neste artigo, outros autores utilizam um abordagem com estudantes no sétimo ano que utiliza conceitos matemáticos como ângulos dentro do ambiente Code.org [Castro et al. 2016]. Utilizando uma linguagem de blocos com comandos similares à Caneta do Scratch e à screen turtle, os estudantes puderam experimentar a resolução de diversos quebra-cabeças. Os resultados apontam uma melhora significativa no rendimento dos alunos. Em outro trabalho, são apresentadas atividades para a melhoria da fluência digital associadas a aspectos lógico-matemáticos na construção de jogos eletrônicos [Castro et al. 2016]. A abordagem foi realizada com turmas de sétimo e oitavo anos com o uso do Scratch.

A questão da fluência digital e do pensamento computacional é abordada em outro trabalho através de um relato de experiência com estudantes de diversos níveis escolares para a criação de animações e jogos [Batista et al. 2016]. Os autores percebem o Scratch como apropriado ao ensino de programação introdutória. Além disso, apontam que, além de ensinar instruções básicas de programação, a experiência favoreceu o raciocínio lógico e estruturado e o desenvolvimento de habilidades para resolver problemas. Outro trabalho apresenta as contribuições do Logo (Turtle) para a geometria, através de uma abordagem com estudantes do sétimo ano [Motta 2010]. Os autores perceberam que as atividades contribuíram para a aprendizagem dos estudantes, desenvolvendo um modelo de pensamento reflexivo. Percebe-se que nosso trabalho está alinhado em relação aos conceitos e ferramentas utilizados em diversas abordagens para o ensino de Computação na escola.

\section{Computação e Comunidade: Uma Proposta para $07^{\circ}$ ano}

Neste trabalho, elaboramos o currículo para o $7^{\circ}$ ano do ensino fundamental, bem como o planejamento das aulas e materiais necessários para a execução deste currículo. Esta é 
VIII Congresso Brasileiro de Informática na Educação (CBIE 2019)

Anais do XXV Workshop de Informática na Escola (WIE 2019)

a segunda etapa de um objetivo maior, que é propor um currículo de Computação para o Ensino Fundamental II, do $6^{\circ}$ ao $9^{\circ}$ anos. Na primeira etapa, que culminou no programa para o $6^{\circ}$ ano, abordamos o tema Computação e Eu onde as experiências de aprendizagem propostas foram projetadas para que os estudantes percebam a computação como uma parte importante de seu mundo, contemplando seus interesses pessoais. Em nossa proposta para o $7^{\circ}$ ano, consideramos que os estudantes estão em transição de um foco em si mesmos para comportamentos orientados ao grupo, e suas esferas sociais estão crescendo além da família, incluindo colegas, professores e outros membros da comunidade. Nesta fase, os estudantes podem apreciar a presença da computação e as maneiras pelas quais a ela facilita a comunicação e a colaboração.

Nossa proposta tem como objetivo principal fomentar o uso do Pensamento Computacional como um meio de resolver problemas relevantes, para os estudantes e para a comunidade ao seu redor. Também pretendemos manter o interesse dos estudantes na Computação como um campo relevante e estimulante. As oportunidades de aprendizagem são apresentadas de maneira ativa e buscam que os estudantes desenvolvam a visão de que eles são solucionadores de problemas, criadores, inovadores e capazes de mudar o mundo. Os aprendizes também devem saber que, com estes conhecimentos, vem a responsabilidade. Por isso, questões de uso ético e responsável da computação também são elementos essenciais deste currículo.

No currículo desta série, os resultados de aprendizagem gerais estão definidos em torno de cinco eixos centrais: Pensamento Computacional; Práticas de Computação e Programação; Colaboração; Computadores e Dispositivos de Comunicação e Impactos Comunitários, Globais e Éticos. Cada um dos eixos possui uma série de tópicos que devem ser cumpridos. Estes tópicos foram selecionados a partir dos cinco eixos do CSTA K-12 Computer Science Standards [Seehorn et al. 2011]. A Figura 1 lista os tópicos que foram considerados na proposta do $7^{\circ}$ ano. O Pensamento Computacional trata de um conjunto de habilidades relacionadas à capacidade de resolver problemas. As Práticas de Computação e Programação envolvem o uso de ferramentas computacionais, principalmente a programação. Colaboração parte da ideia de que a Ciência da Computação é uma disciplina intrinsecamente colaborativa e, neste sentido, os estudantes participam de atividades colaborativas junto aos colegas e professores. Computadores e Dispositivos de Comunicação é um eixo pensado para que os estudantes entendam os elementos dos computadores e dispositivos de comunicação modernos, além de serem apresentados a dispositivos e mídias que podem auxiliá-los em suas atividades de aprendizagem. Impactos Comunitários, Globais e Éticos trabalham os princípios de agir de forma responsável e ética ao usar os computadores, tanto de forma independente quanto com outras pessoas.

\subsection{Proposta de ensino-aprendizagem para $07^{\circ}$ ano}

Nossa abordagem para o $7^{\circ}$ ano foi planejada para 60 horas-aula, com duas horas-aula semanais, que ocorrem conjugadas. Assim como na proposta para o $6^{\circ}$ ano, elaboramos 30 aulas, divididas em quatro unidades de aprendizagem. Nossa abordagem também prevê a necessidade de um laboratório equipado com computadores e acesso à Internet e professor com conhecimentos básicos na área, incluindo noções de algoritmos, programação em linguagens de blocos e conceitos básicos de computação. Além disso, é importante que o laboratório tenha uma quantidade de máquinas que permita aos estudantes trabalharem individualmente. 


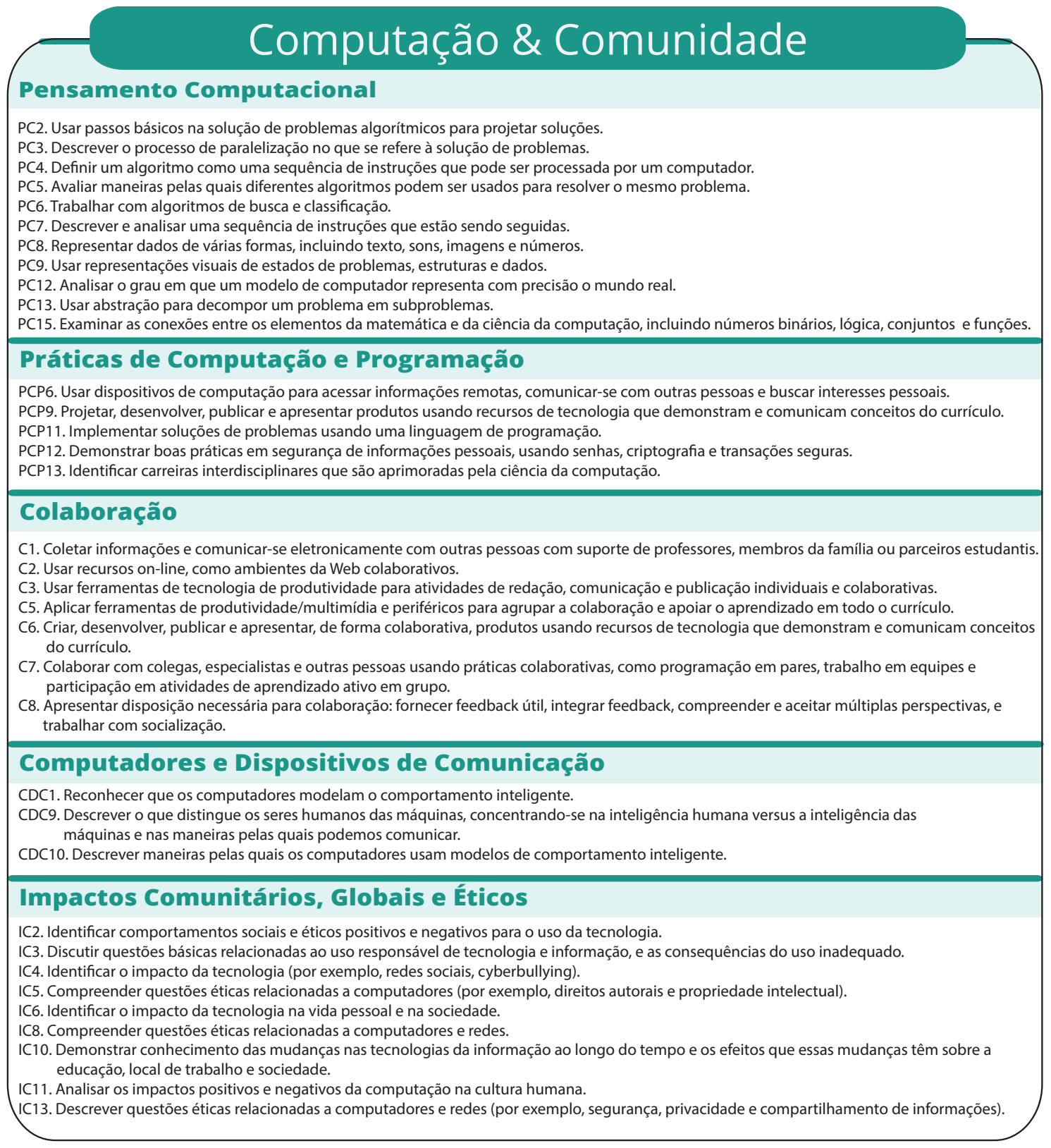

Figura 1. Resultados de Aprendizagem para o $7^{\circ}$ ano.

A Figura 3 lista as aulas de cada unidade, bem como os resultados de aprendizagem esperados e os conteúdos trabalhados. Cada aula aborda um ou mais resultados de aprendizagem esperados. Em todas as unidades, propomos uma natureza diversa de atividades para serem realizadas em sala de aula, como dinâmicas de computação desplugada, desafios de programação e exercícios escritos.

A Unidade I trabalha com programação de desenhos de figuras através da tradicional screen turtle que, no Scratch, encontra-se na categoria de comandos de Caneta. Além disso, nesta unidade, os estudantes devem criar seus perfis na comunidade online do Scratch e, a partir de então, todos os projetos de programação devem ser disponibilizados na comunidade. A última aula desta unidade é destinada a atividades de reflexão sobre o tema de bullying e cyberbullying, evidenciando a responsabilidade dos estudantes 
VIII Congresso Brasileiro de Informática na Educação (CBIE 2019)

Anais do XXV Workshop de Informática na Escola (WIE 2019)

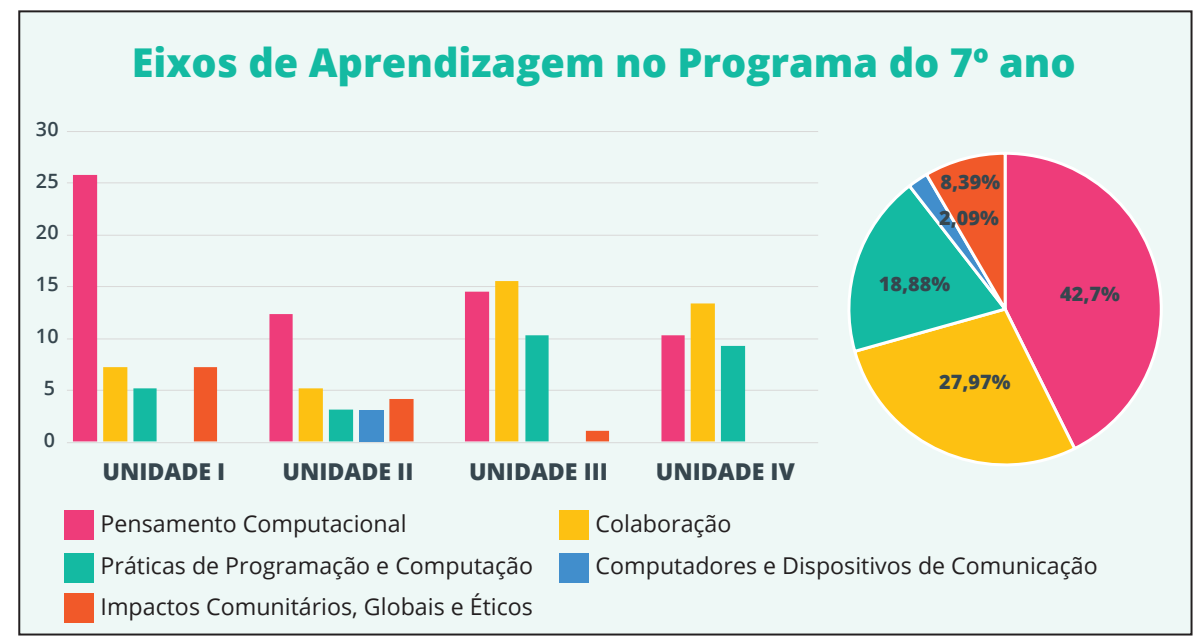

Figura 2. Distribuição dos Resultados de Aprendizagem ao longo do ano.

a necessidade de respeitar os indivíduos presentes nas redes sociais.

A Unidade II trabalha temas variados. Nas primeiras aulas, os estudantes criam programas que exploram as funcionalidades diversificadas do Scratch: webcam, tradutor, fala e editor de música. Na segunda parte desta unidade, os estudantes aprendem sobre a evolução dos computadores e são introduzidos aos temas de busca e inteligência artificial.

As Unidades III e IV buscam aprofundar as habilidades de programação dos estudantes em um contexto do desenvolvimento de jogos 2D com Scratch. Cada aula tem como tema principal a criação de um jogo. São trabalhados diversos padrões de games, como controle pelo teclado, pelo mouse, pela webcam, navegação infinita, turnos ou fases e implementação de escores, dentre outros. Na Unidade III, também incluímos uma aula de computação desplugada que trata sobre autômatos finitos, e uma aula onde os estudantes utilizam ferramentas para a criação de apresentações de slides. Na Unidade IV, reservamos a metade final para que os estudantes criem, em dupla, seu próprio game, a partir de uma lista de requisitos mínimos. Neste projeto final, os estudantes devem aplicar os conhecimentos adquiridos de programação de computadores e pensamento computacional, além de exercer a colaboração com colegas.

A Figura 2 apresenta a distribuição dos tópicos de cada eixo de aprendizagem entre as unidades e a porcentagem com que cada eixo é trabalhado. Pensamento Computacional e Colaboração são os eixos mais trabalhados em todas as unidades. A enfase na colaboração se deve à necessidade de fomentar no estudante o senso de que ele vive e trabalha em comunidade. A categoria Impactos Comunitários, Globais e Éticos aparece nas três primeiras unidades, onde procuramos suscitar nos estudantes o senso de responsabilidade em relação ao uso responsável das redes sociais, de respeito aos indivíduos e de considerar questões de direitos autorais.

\subsection{Estrutura do Livro}

O livro Computação e Comunidade ${ }^{1}$ possui duas versões, uma voltada para professores e outra que pode ser distribuída entre os estudantes. O livro do professor possui diretrizes,

\footnotetext{
${ }^{1}$ Disponível em https://sites.google.com/view/computacaofundamental/
} 
VIII Congresso Brasileiro de Informática na Educação (CBIE 2019)

Anais do XXV Workshop de Informática na Escola (WIE 2019)

instruções gerais e materiais a serem utilizados em sala, enquanto o livro do estudante compila as atividades escritas a serem realizadas em aula e como tarefa para casa.

A versão para professores oferece um guia completo para os educadores responsáveis por ministrar a disciplina. Os capítulos iniciais se destinam à apresentação da proposta, dos eixos que norteiam a nossa abordagem para o $7^{\circ}$ ano e seus respectivos conteúdos de maneira resumida. O restante do livro é dedicado à descrição detalhada das aulas e dos materiais necessários. As aulas estão organizadas de acordo com a sequência apresentada na Figura 3.

Cada aula é descrita através de um plano de aula, que serve para orientar e organizar o trabalho do professor. Cada plano possui, em sua primeira página, o resumo do tema da aula, as habilidades que serão desenvolvidas, os conteúdos que serão trabalhados, a lista das atividades a serem realizadas, os resultados de aprendizagem esperados para a aula e a lista de materiais para a aula, incluindo links para materiais externos. A partir da segunda página, descrevemos o desenvolvimento da aula, que é o passo a passo de como as atividades serão desenvolvidas. Nesta etapa, também descrevemos como os alunos serão organizados, se individualmente, em duplas ou em grupos. Todas as atividades descritas foram pensadas considerando o tempo de duas horas-aula semanais reservado para a disciplina. Materiais como mídias e programas-base para os trabalhos no computador são disponibilizados no site de apoio.

As aulas podem conter, a depender do tema e da natureza das atividades propostas, três outras seções: Tópicos Relevantes, Folha de Tarefas e Tarefa para Casa. A seção Tópicos Relevantes descreve brevemente alguns dos conceitos empregados na aula e deve apoiar os estudantes durante a execução de suas tarefas. A seção Folha de Tarefas possui atividades de escrita ou um guia para as atividades a serem realizadas em sala. A seção Tarefa para Casa é reservada para as atividades extra-classe. Todas estas seções, quando existem, também estão presentes na versão do livro para estudantes.

A versão do estudante possui espaço reservado ao final de cada aula para a escrita de um diário de bordo. No diário de bordo, os estudantes devem expressar suas percepções sobre a aula, o que eles consideram que aprenderam, quais as facilidades e dificuldades enfrentadas e demais reflexões. Além disso, cada aula que envolver projetos de programação possui um lembrete de que projetos devem ser disponibilizados na Comunidade Online do Scratch.

Nossa proposta de disciplina não prevê atividades avaliativas, embora os professores sejam livres para avaliar os estudantes em avaliações somativas através das atividades propostas ou dos projetos disponibilizados pelos estudantes na comunidade online. Os professores também podem usar os diários de bordo escritos pelos estudantes como feedback útil para aprimoramento das estratégias empregadas, buscando aumentar o engajamento dos estudantes no processo de ensino-aprendizagem.

\section{Experiência Preliminar}

Para a aplicação dos materiais do livro, buscamos por escolas que concordassem com sua aplicação. Em virtude da indisponibilidade de aplicação em turmas do sétimo ano, optamos pela aplicação em uma turma de idade mais avançada. Embora a idade dos estudantes seja maior que a idade média dos alunos de uma turma do sétimo ano, esta aplicação não 
VIII Congresso Brasileiro de Informática na Educação (CBIE 2019)

Anais do XXV Workshop de Informática na Escola (WIE 2019)

\begin{tabular}{|c|c|c|}
\hline & AULA & CONTEÚDO \\
\hline \multirow{8}{*}{$\begin{array}{l}-\bar{u} \\
\text { un } \\
\frac{2}{2} \\
\frac{2}{2}\end{array}$} & $\begin{array}{l}1 \text { Desenhando Figuras } \\
\mathrm{PC} 2, \mathrm{PC} 4, \mathrm{PC} 5, \mathrm{PC} 15 \text { e } C 7\end{array}$ & $\begin{array}{l}\text { Sequências; Plano Cartesiano; Ângulos; } \\
\text { Comandos de Movimento e Caneta. }\end{array}$ \\
\hline & $\begin{array}{l}2 \text { Desenhando como um Artista } \\
P C 2, P C 4, P C 5 \text { e } P C 13\end{array}$ & $\begin{array}{l}\text { Loops; Plano Cartesiano; Ângulos; } \\
\text { Comandos de Caneta, Movimento e Controle. }\end{array}$ \\
\hline & $\begin{array}{l}3 \text { Criando meus próprios blocos } \\
P C 2, P C 4, P C 5, P C 7, P C 8, P C 13, P C 15, \text { e PCP11 }\end{array}$ & Comandos de Caneta, Controle, Movimento e Meus Blocos. \\
\hline & $\begin{array}{l}4 \text { Criptografia } \\
\text { PCP12, IC6, IC8 e IC13 }\end{array}$ & $\begin{array}{l}\text { Criptografia; Segurança na troca de informações; } \\
\text { Cifra de César. }\end{array}$ \\
\hline & $\begin{array}{l}5 \text { Explorando a Rede Social do Scratch } \\
P C P 6, P C P 12, C 1, C 2,1 C 5 \text { e IC8 }\end{array}$ & Redes sociais; Scratch; Comunidade online do Scratch. \\
\hline & $\begin{array}{l}6 \text { Desenhando figuras de maneira mais inteligente } \\
P C 2, P C 4, P C 5, P C 7, P C 8, P C 13, P C 15 \text {. e } P C P 11\end{array}$ & $\begin{array}{l}\text { Plano Cartesiano; Ângulos; Loops, Condicionais e Funçōes; } \\
\text { Comandos de Caneta, Controle, Movimento e Meus Blocos. }\end{array}$ \\
\hline & $\begin{array}{l}7 \text { Desafio das Bandeiras } \\
P C 2, P C 5, P C P 11, P C 13, C 7 \text { e } C 8\end{array}$ & $\begin{array}{l}\text { Plano Cartesiano; Ângulos; Comandos de Controle, Caneta, } \\
\text { Movimento, Eventos e Meus Blocos. }\end{array}$ \\
\hline & $\begin{array}{l}8 \text { Falando sobre Bullying } \\
\text { IC2 eIC4 }\end{array}$ & Bullying; Cyberbullying. \\
\hline \multirow{7}{*}{$\begin{array}{l}\frac{2}{2} \\
\frac{1}{2} \\
\frac{2}{2} \\
\frac{2}{2}\end{array}$} & $\begin{array}{l}1 \text { Criando Programas que Falam } \\
P C 2, P C 3 \text { e } P C P 11\end{array}$ & $\begin{array}{l}\text { Sequências; Comandos de Movimento, Aparência, } \\
\text { Controle, Eventos, Texto para Fala. }\end{array}$ \\
\hline & $\begin{array}{l}2 \text { Criando um Tradutor } \\
\text { PC2, } P C 3, P C P 11 \text { e } C 7\end{array}$ & $\begin{array}{l}\text { Sequências; Comandos de Controle, Eventos, } \\
\text { Texto para Fala e Tradução. }\end{array}$ \\
\hline & $\begin{array}{l}3 \text { Compondo Músicas } \\
\mathrm{PC} 2, \mathrm{PC} 3 \text { e } \mathrm{PCP} 11\end{array}$ & $\begin{array}{l}\text { Sequências; Execução de comandos paralelos; Comandos } \\
\text { de Controle, Eventos e Música; Editor de Áudio do Scratch. }\end{array}$ \\
\hline & $\begin{array}{l}4 \text { Brincando com a Webcam } \\
P C 2, P C 3 \text { e PCP } 11\end{array}$ & $\begin{array}{l}\text { Sequência, condicionais e loops; Comandos de Controle, } \\
\text { Eventos, Aparência e Detecção de Vídeo. }\end{array}$ \\
\hline & $\begin{array}{l}5 \text { Passado, Presente e Futuro da Computação } \\
\text { C7, IC2, IC } 3, I C 10 \text { e IC11 }\end{array}$ & $\begin{array}{l}\text { Evolução dos Computadores; } \\
\text { Impacto dos computadores na sociedade. }\end{array}$ \\
\hline & $\begin{array}{l}6 \text { Como os Computadores Buscam Coisas } \\
\text { PC5 e } C 7\end{array}$ & $\begin{array}{l}\text { Busca Linear; Busca Binária; Comparação de valores } \\
\text { numéricos; Coordenadas e plano cartesiano. }\end{array}$ \\
\hline & $\begin{array}{l}7 \text { Inteligência Artificial } \\
P C 2, P C 12, P C P 11, C D C 1, C D C 9 \text { e CDC10 }\end{array}$ & $\begin{array}{l}\text { Inteligência Artificial; Sequências e condicionais; Comandos } \\
\text { de Controle, Eventos, Variáveis, Operadores, Aparência e Sons. }\end{array}$ \\
\hline \multirow{8}{*}{ 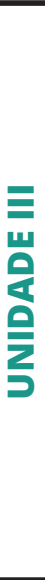 } & $\begin{array}{ll}1 & \text { Caminho Livre! } \\
\text { PC2, PC13, PCP9, PCP11, PCP13, C6, e C7 }\end{array}$ & $\begin{array}{l}\text { Loops, condicionais e eventos; Comandos de Movimento, } \\
\text { Aparência, Controle, Eventos e Sensores. }\end{array}$ \\
\hline & $\begin{array}{l}2 \text { Pegue a Toupeira! } \\
\text { PC2, PC13, PCP9, PCP11, PCP13, C6, e C7 }\end{array}$ & $\begin{array}{l}\text { Loops, condicionais, funções e eventos; Comandos de } \\
\text { Movimento, Aparência, Controle, Operadores, Eventos } \\
\text { e Meus Blocos. }\end{array}$ \\
\hline & $\begin{array}{l}3 \text { O Gato e o Rato! } \\
\text { PC2, PC13, PCP9, PCP11 e C6 }\end{array}$ & $\begin{array}{l}\text { Loops, condicionais e eventos; Comandos de Movimento, } \\
\text { Aparência, Sons, Controle, Eventos e Sensores. }\end{array}$ \\
\hline & $\begin{array}{l}4 \text { Caça ao Tesouro } \\
\text { PC7 e PC9 }\end{array}$ & Autômatos Finitos. \\
\hline & $\begin{array}{ll}5 & \text { Pegue o Queijo! } \\
& P C 2, P C 13, P C P 9, P C P 11 \text { e } C 6\end{array}$ & $\begin{array}{l}\text { Loops, condicionais, sensores e eventos; Comandos de Movi- } \\
\text { mento, Aparência, Controle, Operadores, Sensores e Eventos. }\end{array}$ \\
\hline & $\begin{array}{l}6 \text { Fazendo Apresentações } \\
\text { PCP9 e } C 3\end{array}$ & $\begin{array}{l}\text { Funcionalidades básicas de ferramentas de escritório } \\
\text { para criação de slides; Busca na web. }\end{array}$ \\
\hline & $\begin{array}{l}7 \text { Corte as Frutas! } \\
P C 2, P C 13, P C P 9, P C P 11, C 6, C 5 \text { e } C 7\end{array}$ & $\begin{array}{l}\text { Loops, condicionais e eventos; Comandos de Movimento, Apa- } \\
\text { rência, Sons, Controle, Eventos, Sensores e Detecção de Vídeo. }\end{array}$ \\
\hline & $\begin{array}{l}8 \text { T-Rex no Deserto } \\
\text { PC2, PC13, PCP9, PCP11 e C6 }\end{array}$ & $\begin{array}{l}\text { Loops, condicionais e eventos; Comandos de Movimento, } \\
\text { Aparência, Controle, Operadores e Eventos. }\end{array}$ \\
\hline \multirow{7}{*}{$\begin{array}{l}z \\
\text { zu } \\
2 \\
2 \\
2 \\
z\end{array}$} & $\begin{array}{ll}1 & \text { Interlagos! } \\
& P C 2, P C 13, P C P 9, P C P 11 \text { e } C 7\end{array}$ & \multirow{5}{*}{$\begin{array}{l}\text { Loops, condicionais e eventos; } \\
\text { Comandos de Movimento, Aparência, Controle, } \\
\text { Eventos, Meus Blocos e Sensores. }\end{array}$} \\
\hline & $\begin{array}{l}2 \text { Pegue o Porco } \\
\text { PC2, PC13, PCP9, PCP11 e PCP13 }\end{array}$ & \\
\hline & $\begin{array}{ll}3 & \text { Space Invaders } \\
\text { PC2, } P C 13, P C P 9 \text { e } P C P 11\end{array}$ & \\
\hline & $\begin{array}{l}4 \text { Construindo meu próprio Jogo } \\
P C 2, P C 13, P C P 9, P C P 11, C 6 \text { e } C 7\end{array}$ & \\
\hline & $\begin{array}{|ll|}5 & \text { Finalizando o meu Jogo } \\
& P C 2, P C 13, P C P 9, P C P 11, C 6 \text { e } C 7 \\
\end{array}$ & \\
\hline & $\begin{array}{l}6 \text { Criando a Apresentação do Meu Jogo } \\
P C P 9, C 3, C 6 \text { e } C 7\end{array}$ & $\begin{array}{l}\text { Funcionalidades básicas de ferramentas de escritório para } \\
\text { criação de slides. }\end{array}$ \\
\hline & $\begin{array}{l}7 \text { O Grande Dia } \\
\text { PCP9, C3, C6 e C7 }\end{array}$ & $\begin{array}{l}\text { Criação de Games; } \\
\text { Apresentação multimídia. }\end{array}$ \\
\hline
\end{tabular}

Figura 3. Organização das aulas. 
VIII Congresso Brasileiro de Informática na Educação (CBIE 2019)

Anais do XXV Workshop de Informática na Escola (WIE 2019)

compromete a nossa avaliação, por dois motivos: i) os materiais e atividades são criados com base no nível cognitivo dos alunos do sétimo ano; ii) o objetivo da aplicação foi avaliar a sequência das instruções e atividades, assim como os materiais desenvolvidos.

Os materiais do livro foram aplicados em uma escola estadual. As aulas foram ministradas por um dos autores deste artigo. A abordagem contou com o auxílio de um estudante do curso de Engenharia da Computação e o acompanhamento do professor responsável pela disciplina. A turma participante tinha nove estudantes sem experiência prévia em programação, todos do $2^{\circ}$ ano do ensino técnico em Informática (6 meninos e 3 meninas) com idade média de 15 anos (desvio padrão de 0,53).

Aplicamos parcialmente os materiais do livro, mais especificamente, atividades das Unidades I e IV. No primeiro dia, os estudantes aprenderam os conceitos de algoritmos em sequência e de plano cartesiano. As atividades consistiram em criar linhas e quadrados usando a Caneta no Scratch. Além da Caneta, conceitos sobre movimento e ângulos foram abordados. Os estudantes demonstraram facilidade ao criar as figuras solicitadas.

No segundo dia, os estudantes utilizaram os conceitos aprendidos na aula anterior na criação de novas figuras: triângulos e estrelas. Eles apresentaram maior dificuldade na criação de figuras com ângulos não retos. Alguns concluíram a atividade através de tentativa e erro, avaliando a correção através do feedback visual. A figura da estrela foi a mais desafiadora, dada a mudança de ângulos para criar sua segunda parte. No entanto, através do suporte do professor e do monitor, todos finalizaram as atividades.

No terceiro dia, os estudantes conheceram as estruturas de repetição. Inicialmente, replicaram os códigos das figuras utilizando loops (e.g., quadrado). Em seguida, criaram imagens com vários quadrados e círculos. Eles entenderam que os loops possibilitam a simplificação do código. Por outro lado, para eles, a quantidade de comandos utilizados tornou a atividade mais complexa. No quarto dia, aplicaram os conceitos de loops para criar variações das figuras da aula anterior, modificando a cor e espessura da caneta, gerando imagens diversificadas. Estas atividades em que eles modificam os desenhos se mostram relevantes por exercitar a criatividade.

No quinto dia, os estudantes criaram figuras compostas por diversas figuras geométricas. A atividade consistiu em criar casas utilizando quadrados, retângulos, triângulos e outras figuras vistas em sala.

Além do uso da caneta, utilizamos duas aulas para a criação de um jogo com Scratch. O jogo apresentado foi o Space Invaders, onde os estudantes trabalharam com diversos conceitos: variáveis, condicionais e loops. Percebemos que todas as sequências didáticas estavam claras e possibilitaram ao professor a aplicação do material. Quanto aos estudantes, percebemos que as atividades possuem uma sequência didática apropriada e que os exemplos com imagens facilitam a compreensão por conta do feedback visual.

\section{Discussão}

Após a nossa experiência preliminar, algumas lições aprendidas ficaram evidentes, tais como a forte relação entre computação e matemática, a possibilidade de oferecer um meio de expressão artística para os aprendizes, e uma melhor avaliação dos materiais.

Computação ajuda com a Matemática (e vice-versa). A Computação oferece uma gama de possibilidades para trabalhos interdisciplinares. Dentre as possibilidades 
VIII Congresso Brasileiro de Informática na Educação (CBIE 2019)

Anais do XXV Workshop de Informática na Escola (WIE 2019)

vislumbradas, a forte relação entre Computação e Matemática merece destaque. Trabalhar com Turtle envolve orientação no plano cartesiano e conhecimentos sobre ângulos e, para que seja possível trabalhar com ideias mais complexas de algoritmos, fazer correspondência com as propriedades de polígonos regulares. Aulas sobre jogos também trabalham com outros conceitos, como operadores de comparação e variáveis. Estes conteúdos fazem parte do currículo de matemática, e podem ser ensinados ou reforçados em um contexto de aprendizagem de programação, ajudando a manter o interesse da turma e a percepção de relevância. Em contrapartida, a base que os estudantes já possuem de matemática influi no tempo e no modo como a programação é aprendida.

A Computação oferece um meio de expressão artística. Em nossa proposta, apresentamos aos estudantes diversas maneiras pelas quais eles podem utilizar a Computação como um meio de expressão. Desde o primeiro livro, voltado para o $6^{\circ}$ ano, consideramos as maneiras pelas quais os estudantes podem expressar seus gostos e interesses. Nessa proposta para o $7^{\circ}$ ano, continuamos a evidenciar a Computação como um meio de expressão pois, ao oferecer a possibilidade de criação de desenhos diversos, Turtle também oferece um meio de expressão artística. Em nossa experiência preliminar, percebemos o aumento da atenção dos estudantes e do empenho destes diante da possibilidade de modificar as cores, espessura da caneta e criar novas figuras, aplicando variações com condicionais. Além disso, também trabalhamos com os estudantes a possibilidade de apresentar seus projetos para o mundo através da comunidade online do Scratch.

A necessidade de avaliar e ajustar as práticas de acordo com o grupo ensinado. O objetivo da experiência realizada foi avaliar a sequência das instruções e atividades, assim como os materiais desenvolvidos, mas não empregamos nenhuma avaliação especifica sobre aprendizagem devido à diferença de idade entre o grupo aplicado e a série para qual o material foi desenvolvido. No entanto, nossa breve experiência evidenciou a necessidade de considerar cada turma individualmente e, dentro de uma mesma turma, os diferentes ritmos de aprendizagem ao aplicar a abordagem proposta. Apesar de oferecermos um currículo, com planos de aula e materiais de apoio, não oferecemos apenas uma fórmula empacotada para o ensino de computação, mas sugestões que podem e devem ser adaptadas de acordo com os interesses e as potencialidades de cada turma.

\section{Conclusões}

Neste trabalho, apresentamos o currículo e um livro didático de computação para o sétimo ano do Ensino Fundamental II. Ambos foram baseados no domínio de conceitos e tecnologias da computação e no desenvolvimento do pensamento computacional. Para avaliação preliminar, aplicamos parte dos materiais do livro em uma escola pública estadual e discutimos as principais lições aprendidas.

Como síntese das lições aprendidas, destacamos a integração da computação com a matemática, a computação como meio de expressão artística e a necessidade de avaliar e ajustar as práticas de acordo com o grupo de aprendizes.

Os benefícios trazidos pelo currículo e pelo livro didático propostos estão diretamente ligados à popularização da introdução à computação no ensino fundamental brasileiro. Professores passam a contar com um recurso concreto de apoio a aulas de computação, enquanto que aprendizes constroem um espaço de discussão e prática de tecnologias atuais e habilidades fundamentais no século XXI. 
VIII Congresso Brasileiro de Informática na Educação (CBIE 2019)

Anais do XXV Workshop de Informática na Escola (WIE 2019)

Pretendemos, no futuro, avaliar a utilização integral do livro em um ano escolar completo com turmas do sétimo ano do ensino fundamental.

\section{Agradecimentos}

Este projeto foi apoiado pela FAPESP através do auxílio de pesquisa 2015/24331-1 e das bolsas de treinamento técnico 2018/12799-7 e 2018/15614-8.

\section{Referências}

Barr, D., Harrison, J., and Conery, L. (2011). Computational thinking: A digital age skill for everyone. Learning \& Leading with Technology, 38(6):20-23.

Batista, E. J. S., Castro Jr, A., Cantero, S., Bogarim, C. A. C., and Larrea, A. A. (2016). Uso do Scratch no Ensino de Programação em Ponta Porã: das Séries Iniciais ao Ensino Superior. In Anais do Workshop de Informática na Escola.

Castro, M. C., Werneck, V., and Gouvea, N. (2016). Ensino de Matemática através de Algoritmos Utilizando Jogos para Alunos do Ensino Fundamental II. In Anais dos Workshops do Congresso Brasileiro de Informática na Educação.

Guzdial, M. (2004). Introduction to Media Computation: A Multimedia Cookbook in Python. Pearson.

Hazzan, O., Gal-Ezer, J., and Blum, L. (2008). A Model for High School Computer Science Education: The Four Key Elements That Make It! In Proceedings of the 39th Technical Symposium on Computer Science Education, pages 281-285. ACM.

Motta, M. S. (2010). Contribuições do Superlogo ao Ensino de Geometria. Informática na educação: teoria \& prática, 13(1).

Resnick, M., Maloney, J., Monroy-Hernández, A., Rusk, N., Eastmond, E., Brennan, K., Millner, A., Rosenbaum, E., Silver, J., Silverman, B., et al. (2009). Scratch: Programming for all. Communications of the ACM, 52(11):60-67.

Royal Society (2012). Shut down or restart? The way forward for computing in UK schools. The Royal Society, London.

Santana, B. L., Araujo, L. G. J., and Bittencourt, R. A. (2019). Computação e Eu: Uma Proposta de Educação em Computação para o Sexto Ano do Ensino Fundamental II. In WEI 2019 - XXVII Workshop sobre Educação em Computação.

Santos, P. S., Araujo, L. G. J., and Bittencourt, R. A. (2018). A Mapping Study of Computational Thinking and Programming in Brazilian K-12 Education. In 2018 IEEE Frontiers in Education Conference (FIE), pages 1-8. IEEE.

SBC (2017). Referenciais de Formação em Computação: Educação Básica. http://www.sbc.org.br/files/ ComputacaoEducacaoBasica-versaofinal-julho2017.pdf.

Seehorn, D., Carey, S., Fuschetto, B., Lee, I., Moix, D., O’Grady-Cunniff, D., Owens, B. B., Stephenson, C., and Verno, A. (2011). CSTA K-12 Computer Science Standards: Revised 2011. Technical report, CSTA/ACM, New York, NY, USA. 104111.

Wing, J. M. (2006). Computational thinking. Communications of the ACM, 49(3):33-35. 